\title{
Poor immune status and systemic disease are independently associated with mortality in AIDS-related Kaposi Sarcoma in Nigeria
}

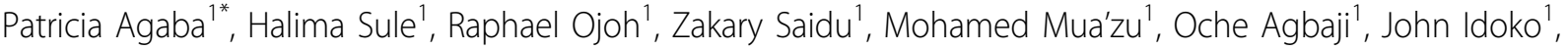 \\ Ernest Ekong ${ }^{2}$, Robert Murphy ${ }^{3}$, Phyllis Kanki ${ }^{4}$
}

From 13th International Conference on Malignancies in AIDS and Other Acquired Immunodeficiencies (ICMAOI)

Bethesda, MD, USA. 7-8 November 2011

\section{Background}

AIDS-related Kaposi's sarcoma (AIDS-KS) is the most common AIDS-associated malignancy and remains a significant cause of morbidity and mortality in subSaharan Africa. We describe the determinants of mortality among patients with AIDS-KS in a comprehensive HIV care and treatment program in Jos, Nigeria.

\section{Material and methods}

We collected epidemiologic, clinical, staging and survival data for 357 patients with a diagnosis of AIDS-KS enrolling for HIV-care at the Jos University Teaching Hospital. Patients were staged according to the AIDS Clinical Trials Group (ACTG) criteria, which are based on the evaluation of tumor extension (T), CD4+ cell count (I), and patient's systemic status (S), stratified by good (0) versus poor (1) risk. Information on survival was obtained through an active follow-up on verification of vital status of the patients. Survival analysis was computed by the KaplanMeier method, and the log-rank test was used to test the difference between subgroups.

\section{Results}

During the period of the study (2004-2008), there were 197 women (55.2\%) and 160 (44.8\%) men with AIDSrelated Kaposi Sarcoma. Their mean age was $37 \pm 8$ years and the median follow-up was 15 months (1-49 months). The median CD4+ and viral load were $107 \mathrm{cells} / \mathrm{mm}^{3}$ and 58,561 copies/ml respectively at baseline. Only 42 (11.8\%) were on HAART at KS diagnosis, however all patients were commenced on HAART in line with existing national guidelines subsequently. 262(74.4\%) had poor immune system status (I1: CD4+<200cells $/ \mathrm{mm}^{3}$ ), $77.5 \%$ had widespread tumor extension (T1) and $80.2 \%$ had systemic disease (S1). Poor immune system (I1) status (AOR 2.07, CI 1.25-3.42, $\mathrm{p}=0.002)$ and presence of systemic disease (S1) (AOR 2.10, CI 1.03-4.28, $\mathrm{p}=0.004$ ) were independently associated with mortality.

Regarding ACTG classification, the 4-year survival rate was $67 \%$ for I0 vs $46 \%$ for I1 ( $\mathrm{p}=0.05), 58 \%$ for S0 vs $49 \%$ for $\mathrm{S} 1(\mathrm{p}=0.41), 60 \%$ for T0 vs $46 \%$ for $\mathrm{T} 1$ ( $\mathrm{p}=0.19)$.

\section{Conclusion}

Poor immune status and systemic disease are independent predictors of mortality in patients with AIDS-KS in Nigeria.

\section{Author details}

${ }^{1}$ APIN Centre, Jos University Teaching Hospital, Jos, Nigeria. ${ }^{2}$ AIDS Prevention Initiative Nigeria Plus, Abuja, Nigeria. ${ }^{3}$ Northwestern University Medical School, Chicago, IL, USA. Immunology and Infectious Diseases, Harvard School of Public Health, Boston, MA, USA.

Published: 19 April 2012

doi:10.1186/1750-9378-7-S1-P7

Cite this article as: Agaba et al:: Poor immune status and systemic disease are independently associated with mortality in AIDS-related Kaposi Sarcoma in Nigeria. Infectious Agents and Cancer 2012 7(Suppl 1): P7.

\footnotetext{
* Correspondence: ellagaba@yahoo.com

${ }^{1}$ APIN Centre, Jos University Teaching Hospital, Jos, Nigeria

Full list of author information is available at the end of the article
}

๑ 2012 Agaba et al; licensee BioMed Central Ltd. This is an open access article distributed under the terms of the Creative Commons 